\begin{tabular}{|c|l|}
\hline Title & A One pot Synthesis of Terminal A lkynes from anti-3-A ryl-2,3-dibromopropanoic A cids under Microwave Irradiation \\
\hline Author(s) & Kuang, Chunxiang; Senboku, Hisanori; Tokuda, Masao \\
\hline Citation & $\begin{array}{l}\text { Chemistry Letters, 34(1), 28-29 } \\
\text { https://doi.org/10.1246/1.2005.28 }\end{array}$ \\
\hline Issue Date & 2005-01-05 \\
\hline Doc URL & http://hdl.handle.net/2115/70910 \\
\hline Type & article \\
\hline File Information & cl2005.28.pdf \\
\hline
\end{tabular}

Instructions for use 


\title{
A One-pot Synthesis of Terminal Alkynes from anti-3-Aryl-2,3-dibromopropanoic Acids under Microwave Irradiation
}

\author{
Chunxiang Kuang, ${ }^{* \dagger}$ Hisanori Senboku, ${ }^{\dagger \dagger}$ and Masao Tokuda ${ }^{\dagger \dagger}$ \\ ${ }^{\dagger}$ Department of Materials Chemistry, Graduate School of Engineering, Osaka University, Toyonaka 560-0043 \\ ${ }^{\dagger}$ Division of Molecular Chemistry, Graduate School of Engineering, Hokkaido University, Sapporo 060-8628
}

(Received October 4, 2004; CL-041168)

\begin{abstract}
A facile one-pot synthesis of terminal alkynes was achieved by microwave irradiation of a mixture of anti-3-aryl-2,3-dibromopropanoic acids, $\mathrm{Et}_{3} \mathrm{~N}$ and $\mathrm{DMF}$ and subsequent irradiation in the presence of 1,8-diazabicyclo[5.4.0]undec-7-ene (DBU). This method requires short reaction time (1-2 min) and gives terminal alkynes in high yields.
\end{abstract}

Terminal alkynes are useful and versatile intermediates in organic synthesis. Most frequently used methods for the conversion of aldehydes to terminal alkynes include the reactions of Corey-Fuchs, ${ }^{1}$ Wittig/Horner-Emmons, ${ }^{2}$ and GilbertSeyferth, ${ }^{3}$ and its modification. ${ }^{4}$ However, the need for phosphorus reagents limits the usefulness of these applications due to toxicity, exothermicity, and voluminous waste stream, particularly for large-scale preparations. Recently, Wang et al. have reported a procedure for the synthesis of terminal alkynes from aldehydes through a three-step reaction sequence: addition of dihalomethyllithium to aldehyde, sulfonation of the adducts, and then elimination of chloride and tosylate followed by elimination of HX to generate the desired alkynes. ${ }^{5}$ However, this synthetic method also has several drawbacks, such as the use of arylsulfonyl chloride and excess organolithium, and very low temperature.

In 1997, Matveeva et al. reported that the ( $Z$ )-vinyl bromides could be converted into the corresponding acetylenes in the presence of alkoxides in a moderate yields. ${ }^{6}$ On the other hand, our previous study showed that microwave irradiation of anti-2,3-dibromopropanoic acids (1) in DMF in the presence of triethylamine for $0.5-1.0 \mathrm{~min}$ stereoselectively afforded $(Z)$ vinyl bromides (2) in nearly quantitative yields (Scheme 1). ${ }^{7}$

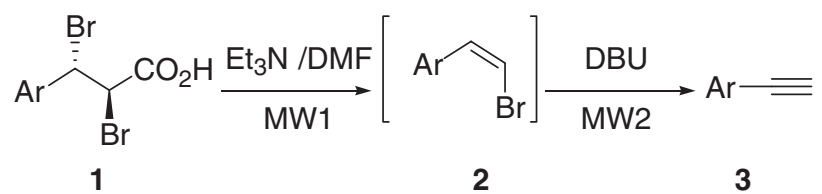

Scheme 1. One-pot synthesis of terminal alkynes.

In this paper, we report a very simple and general method for the synthesis of terminal alkynes (3) from anti-3-aryl-2,3dibromopropanoic acids by microwave irradiation method (Scheme 1). The starting anti-3-aryl-2,3-dibromopropanoic acids were easily prepared by Knoevenagel condensation of the corresponding aldehydes and subsequent bromination of the substituted trans-cinnamic acids. ${ }^{8}$ To the best of our knowledge, the one-pot synthesis of terminal alkynes from anti-3-aryl2,3-dibromopropanoic acids has not been reported.

Various conditions were examined to optimize the yields of terminal alkynes. In the first step (MW1), treatment of anti-3-aryl-2,3-dibromopropanoic acids with triethylamine in DMF under microwave irradiation within $0.5-1.0$ min resulted in $(Z)-1$-bromo-1-alkenes with the high $Z / E$ selectively and excellent yields. As to the second step (MW2), it was found that bases such as $\mathrm{Et}_{3} \mathrm{~N}$, pyridine, DABCO, $\mathrm{NaOH}, \mathrm{K}_{2} \mathrm{CO}_{3}$, or $t$ - $\mathrm{BuOK}$ were not effective in this one-pot reaction. DBU was found to be the best base in this one-pot system. DBU is not typically used to convert vinyl halides into alkynes, in general, this conversion requires alkoxides. ${ }^{6}$ Schuda et al. have reported that $(Z)$-vinyl bromide was nearly quantitatively converted into terminal alkynes in 2 days with DBU in refluxing benzene and that the corresponding (E)-isomer did not react with DBU. ${ }^{9} \mathrm{We}$ found that under microwave irradiation the reaction of anti-3-aryl-2,3-dibromopropanoic acids and triethylamine in DMF followed by addition of 1,8-diazabicyclo[5.4.0] undec-7-ene (DBU) proceeded smoothly to afford the corresponding terminal alkynes in high yields. ${ }^{10}$

Yields of the terminal alkynes (3) are shown in Table 1. These results indicate that terminal alkynes were obtained in higher yields and in shorter reaction time by the microwave irradiation method. It would be very convenient for this one-pot reaction to use same base in two successive steps. Unfortunately,

Table 1. One-pot synthesis of terminal alkynes by microwave irradiation of anti-3-aryl-2,3-dibromopropanoic acids

\begin{tabular}{|c|c|c|c|c|c|}
\hline Entry & Ar of 1 & Product (3) & & $\begin{array}{c}\text { MW1 / MW2 } \\
\text { min }\end{array}$ & $\begin{array}{c}\text { Yield of } 3 \\
\%^{\mathrm{a}}\end{array}$ \\
\hline 1 & $\mathrm{C}_{6} \mathrm{H}_{5}-$ & & 3a & $0.5 / 1.0$ & 88 \\
\hline 2 & 2-Naphthyl & & $3 b$ & $0.5 / 1.0$ & 95 \\
\hline 3 & 4- $\mathrm{BrC}_{6} \mathrm{H}_{4}-$ & & $3 c$ & $1.0 / 1.0$ & 95 \\
\hline 4 & 4- $\mathrm{ClC}_{6} \mathrm{H}_{4}-$ & & $3 d$ & $1.0 / 1.0$ & 93 \\
\hline 5 & 2- $\mathrm{ClC}_{6} \mathrm{H}_{4}-$ & & $3 e$ & $1.0 / 1.0$ & 90 \\
\hline 6 & 4- $\mathrm{FC}_{6} \mathrm{H}_{4}-$ & & $3 f$ & $1.0 / 1.0$ & 88 \\
\hline 7 & $3-\mathrm{FC}_{6} \mathrm{H}_{4}^{-}$ & & $3 g$ & $1.0 / 1.0$ & 90 \\
\hline 8 & $3-\mathrm{CF}_{3} \mathrm{C}_{6} \mathrm{H}_{4}^{-}$ & & $3 \mathrm{~h}$ & $1.0 / 1.0$ & 91 \\
\hline 9 & 4- $\mathrm{CH}_{3} \mathrm{O}_{2} \mathrm{CC}_{6} \mathrm{H}_{4}^{-}$ & & $3 \mathbf{i}$ & $1.0 / 1.0$ & 99 \\
\hline 10 & 3- $\mathrm{NO}_{2} \mathrm{C}_{6} \mathrm{H}_{4}-$ & & 3j & $1.0 / 1.0$ & 87 \\
\hline
\end{tabular}

${ }^{\mathrm{a}}$ Isolated yields. 
when DBU instead of $\mathrm{Et}_{3} \mathrm{~N}$ was used in the first step, a mixture of (Z)- and (E)-vinyl bromide (approximate to 92/8) was formed, and this stereoselectivity was much lower than those using $\mathrm{Et}_{3} \mathrm{~N}$. Since DBU did only cause an elimination of (Z)-vinyl bromides under these conditions, a mixture of terminal alkynes and unreacted $(E)$-vinyl bromides were obtained.

In summary, we have developed a new procedure for onepot conversion of anti-3-aryl-2,3-dibromopropanoic acids into terminal alkynes in excellent yields within a few minutes by microwave irradiation method which is a economical and environment friendly process.

This work was supported by a Grant-in-Aid for Exploratory Research (No. 13875171) from the Ministry of Education, Culture, Sports, Science and Technology, Japan.

\section{References and Notes}

1 E. J. Corey and P. L. Fuchs, Tetrahedron Lett., 13, 3769 (1972).

2 E. J. Corey, K. Achiwa, and J. A. Katzenellenbogen, J. Am. Chem. Soc., 91, 4318 (1969).

3 J. C. Gilbert and U. Weerasooriya, J. Org. Chem., 47, 1837 (1982).

4 a) S. Müller, B. Liepold, G. J. Roth, and H. J. Bestman, Synlett, 1996, 521. b) G. J. Roth, B. Liepold, S. G. Müller, and H. J. Bestmann, Synthesis, 2004, 59.

5 a) Z. Wang, J. Yin, S. Campagna, J. A. Pesti, and J. M. Fortunak, J. Org. Chem., 64, 6918 (1999). b) Z. Wang, S. Campagna, K. Yang, G. Xu, M. E. Pierce, J. M. Fortunak, and P. N. Confalone, J. Org. Chem., 65, 1889 (2000).

6 a) E. D. Matveeva, A. S. Erin, and A. L. Kurz, Russ. J. Org. Chem., 33, 1065 (1997). b) M. Makosza and A. A. Chesnokov, Tetrahedron, 58, 7295 (2002).
7 C. Kuang, H. Senboku, and M. Tokuda, Tetrahedron Lett., 42, 3893 (2001).

8 a) J. McNulty, J. A. Steere, and S. Wolf, Tetrahedron Lett., 39, 8013 (1998). b) Q. L. Wang, Y. Ma, and B. Zuo, Synth. Commun., 27, 4107 (1997). c) S. H. Kim, H.-X. Wei, S. Willis, and G. Li, Synth. Commun., 29, 4179 (1999).

9 P. F. Schuda and M. R. Heimann, J. Org. Chem., 47, 2484 (1982).

10 Typical experimental procedure is as follows (Table 1, Entry 9): A mixture of anti-2,3-dibromo-3-(4-methoxycarbonylphenyl)propanoic acid (2i, $1 \mathrm{mmol})$ and triethylamine $(1.05 \mathrm{mmol})$ was added to $2 \mathrm{~mL}$ of DMF. The mixture was kept in a microwave oven operated at $2450 \mathrm{MHz}$ (TOSHIBA, ER-V11, 200 watts) and was irradiated for 1.0 min without any stirring. The reaction mixture was then removed from the oven and cooled to room temperature. 1,8Diazabicyclo[5.4.0] undec-7-ene (DBU) (2 mmol) was added to the reaction mixture and the mixture was also irradiated for 1.0 min without any stirring. Water and ether were added to the reaction mixture and the organic layer was separated. Aqueous layer was extracted with ether. The combined organic layers were washed with water and brine, and dried over anhydrous magnesium sulfate. After evaporation of the solvent, the crude product was purified by column chromatography on silica gel with EtOAc-hexane to give methyl 4-ethynylbenzoate (3i) in $99 \%$ yield. $\mathrm{Mp} 94-95^{\circ} \mathrm{C}$; IR (nujol) 2106, 1733, $1275 \mathrm{~cm}^{-1}$; ${ }^{1} \mathrm{HNMR}(270 \mathrm{MHz}$, $\left.\mathrm{CDCl}_{3}\right) \delta 3.23(1 \mathrm{H}, \mathrm{s}), 3.92(3 \mathrm{H}, \mathrm{s}), 7.55(2 \mathrm{H}, \mathrm{d}, J=8.5$ $\mathrm{Hz}), 7.98(2 \mathrm{H}, \mathrm{d}, J=8.5 \mathrm{~Hz}) ;{ }^{13} \mathrm{C} \mathrm{NMR}\left(67.5 \mathrm{MHz}, \mathrm{CDCl}_{3}\right)$ $\delta$ 52.25, 80.00, 82.77, 126.73, 129.43, 130.11, 132.05, 166.39. EIMS $m / z 160\left(\mathrm{M}^{+}, 53\right), 129$ (100), 101 (52); HRMS Calcd for $\mathrm{C}_{10} \mathrm{H}_{8} \mathrm{O}_{2} . m / z \quad 160.0524$. Found $\mathrm{m} / \mathrm{z}$ 160.0508 . 